\title{
THE VALIDITY OF A VISUAL BASIC PROGRAM IN LEARNING CONE BEAM COMPUTED TOMOGRAPHY VERSUS THE POWERPOINT SLIDES
}

\author{
Shereen Abdel Moula Ali ${ }^{*}$, Engy Ali Abdelhaleem Salam ${ }^{* *}$ and Hussein I. Saudi ${ }^{* * *}$
}

\begin{abstract}
Aims: the purpose of this study was to evaluate the validity of specially designed computer assisted learning (CAL) Visual Basic program containing images with multiple choice questions (MCQ) for learning the basics of CT and CBCT compared to lecture supplemented with PowerPoint presentation only.
\end{abstract}

Methodology: The software contained one hundred images obtained from textbooks and internet web sites, the images included the basic principles of CT and CBCT, normal anatomical landmarks, caries, periapical granuloma, cyst and tumor interpretation. 30 postgraduate internship students' participated and divided into two groups after attending a guiding lecture about the cone beam computed tomography including the study images, group I were given the program CD while group II were allowed to review the lecture only. After 2 weeks, both groups had OSPE exam.

Results: it showed statistically significant mean student's score in group I receiving the program $\mathrm{CD}$ after lecture compared to the other group II (traditional method only)

Conclusion: The use of CAL Visual Basic program enhances the learning of the basics of $\mathrm{CBCT}$

KEYWORDS: Visual Basic Program, E-learning, Computer assisted learning, CBCT, Oral radiology education.

\section{INTRODUCTION}

Computers have become an essential part of our personal and professional lives, and an evident result of this is the introduction of personal computers and electronic devices in the fields of teaching and learning.
Compute assisted learning (CAL) is a term significantly increase over years and can be referred as computer based instruction, computer aided learning or computer aided instruction. CAL can be simply define as learning procedures facilitated through computer. ${ }^{[1,2]}$

Assistant Prof. of Oral Medicine, Periodontology, Oral Diagnosis \& Radiology. Faculty of Dentistry, Tanta University. Lecturer, Department of Oral And Maxillofacial Radiology, Faculty of Dentistry, Fayoum University.

Professor of Oral Medicine, Periodontology, Oral Diagnosis \& Radiology. Faculty of Dentistry, Tanta University 
CAL can additionally use multimedia capabilities which can utilize not only texts and images, as traditional methods of learning, but also videos to enhance student learning ${ }^{[3]}$ The complex and high volume of information presented in medical and dental education today has resulted in an ever-increasing number of CAL programs being incorporated into education curricula.

CAL programs designed usually to evaluate the student diagnosis and performance depending on what facts have been accessed, some of these programs utilizing multimedia which depends on the principle of problem based learning. ${ }^{[2,4]}$

It was reported that, CAL program could provide an effective way of learning that could be used interactively as it guides the students through interactive documents such as quizzes with feedback and learning games, which can augment the learning process by providing feedback in a manner that makes students comfortable ${ }^{[5,6]}$, improve motivation and facilitate knowledge consolidation.

In addition, reports supposed that digital environment enables program instructor and teachers to visually display contents efficiently that supporting student participation. ${ }^{[7-9]}$ Instructional presentation software enables instructors to smoothly enhance, change content, and it provides opportunities for animation and placement of materials on a server. Once on the server, students have access to the material at all times. ${ }^{[10]}$

CAL has progressed in recent years to a new approach in the form of blended learning, this blended learning combines the CAL with the traditional methods of learning as lectures. The main advantage of those type of learning is that it integrates the advantages and strength of both methods..$^{[11-13]}$

Research studies, concerning the evaluation of computer program, CAL and blended courses in the dental curriculum, have been performed in many disciplines such as oral medicine ${ }^{[2]}$, orthodontics $^{[14,15]}$, anatomy ${ }^{[16]}$, oral pathology $y^{[17]}$, fixed and removable prosthodontic ${ }^{[18,19]}$, restorative dentistry, endodontics ${ }^{[4,20]}$, dental terminology and oral radiology anatomy ${ }^{[21]}$, physics and interpretation $^{[22]}$.

The concern of the use of advanced technologies in teaching oral and maxillofacial radiology becomes a challenge in the recent years as this specialty is integrated with other areas in dentistry as important aid in diagnosis, treatment planning and prognosis of oral diseases especially with the constant development in the field of digital dentistry with the ability of management, storage and transmission of a larger number of images through computer network as computer file compared to traditional book. ${ }^{[9,23]}$

Cone beam computed tomography (CBCT) has furiously achieved a significant progress in maxillofacial radiology, an advanced imaging modality which has the benefits of rapid scan time, three dimensional image and utilizing cone shaped beam confined to the head and neck region which reducing the radiation dose compared with Computed tomography, also CBCT provide a real time and interactive display that allows reformation of the image in different planes making CBCT valuable for various dental practices. ${ }^{[24-27]}$

As CBCT is beneficial for diagnosis, treatment planning and post-treatment assessment, there should be an accurate theoretical and practical knowledge of CBCT among dental student who are the future clinician. ${ }^{[28]}$

Therefore, the aim of the present study is to evaluate the validity of specially designed computer assisted learning CAL Visual Basic program containing images with multiple choice questions (MCQ) for learning the basics of CT and CBCT compared to lecture supplemented with PowerPoint presentation only. 


\section{MATERIAL AND METHOD}

The software was developed in visual basic 6 language. It contained a picture box on which the images can be loaded, three buttons named according to their functions. The "Question button" was assigned to display a question with three choices for the user to select the correct answer, the Clear button was assigned to clear the present question and the suggested answers and the Exit button was assigned to end the program. The software also contained a horizontal scroll bar from which the images can be selected, by moving its button or pressing the right and left buttons using the mouse. The Help label will display the help message then the help screen when clicked. Moreover, the software contained a label to display the question and three labels for the answers, also the three option buttons allow the username to select one and only one answer while the green label will display the word Correct if the answer is right. Finally, the software had a label displaying the image number (Fig1-7).

The software contained one hundred images obtained from textbooks and internet web sites. The selected images included the basic principles of computed tomography, the main parts of the CT tube head, the CT generations reaching to the principle of CBCT, identification of the axial, coronal, sagittal planes and the reformatted 3D view. The images also included the most common normal landmarks in the mandible, maxilla, nasal bones, maxillary sinuses, infra orbital contents, the lateral parts of the skull besides the normal anatomical landmarks at the base of the skull. Also the images included different types of carries, periapical granuloma, different types of cysts, bone infections, tumors. Moreover, the images included the axial views for the number and shape of the filled and unfilled root canals, bone fracture and other subjects.

Thirty (one year) postgraduate internship students were selected to participate in the study, 15 students from the faculty of dentistry Tanta university and
15 students from Fayoum university, the students were selected after passing an assessment test to identify their entry knowledge about the basics of oral radiology, the students joined to this study on a voluntary basis after being informed about the purpose of the study.

All the participants Students attended a guiding lecture about the cone beam computed tomography including the study images. Students were randomly classified into two groups, fifteen students in each group.

Group I students were given program CD and were instructed how to use it for one week while the students in group II were allowed to review the lecture daily for one week from the Power point slides. After two weeks, the thirty students were grouped once again for an OSPE exam included the hundred slides with thirty seconds for each slide. The slides in this exam were arranged randomly with changing the order of choices.

After completing the test, each participant student was asked to complete a questionnaire to assess the satisfaction regarding the effect of each type of learning lecture with the program and the lecture only.

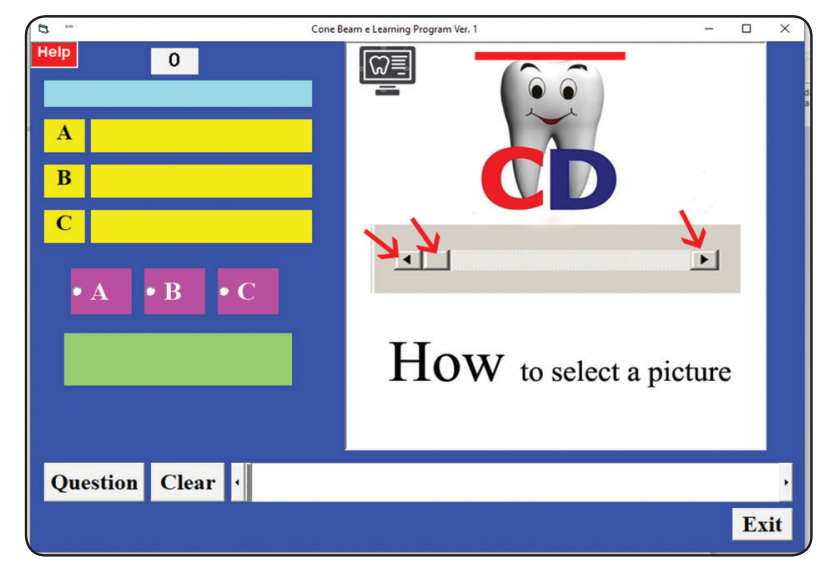

Fig. (1) Software layout showing how to select a picture after pressing the help bottom using the horizontal scroll bar (red arrows) and how to display the question pressing on question bottom (black arrow). 


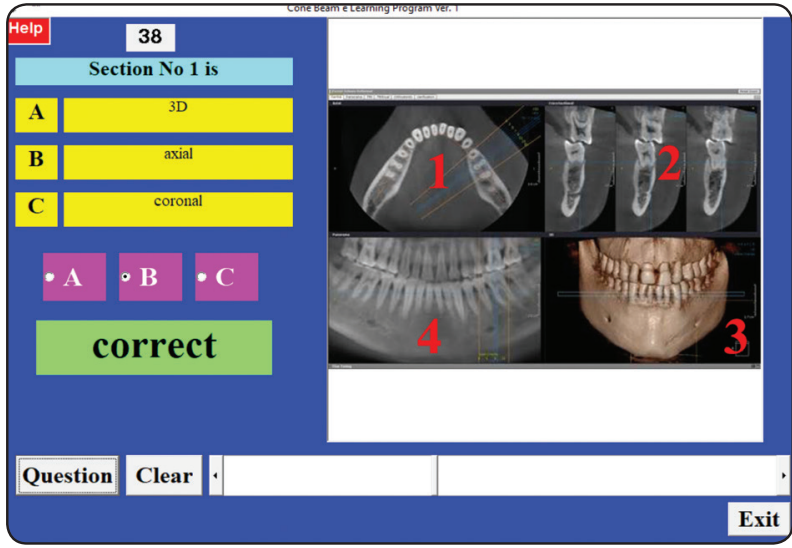

Fig. (2) Software layout displaying a MCQ about CBCT multiplaner views.

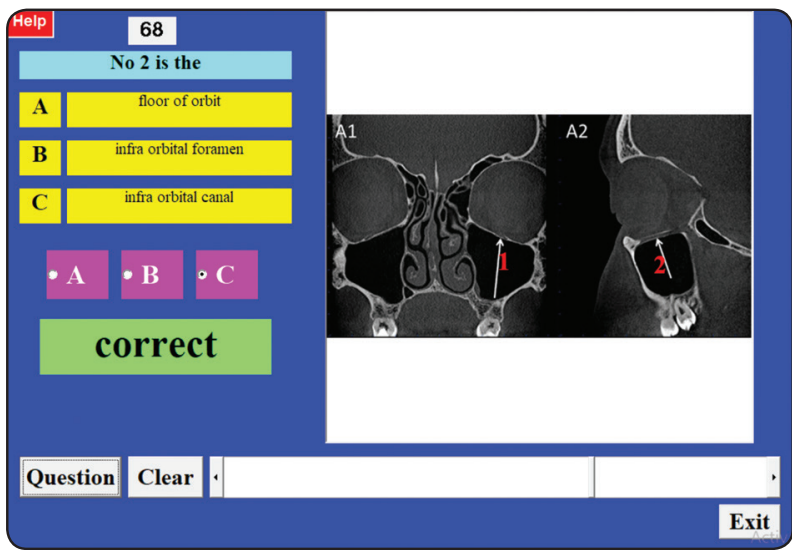

Fig. (4) Software layout displaying a MCQ about normal maxillary anatomical landmarks on CBCT image.

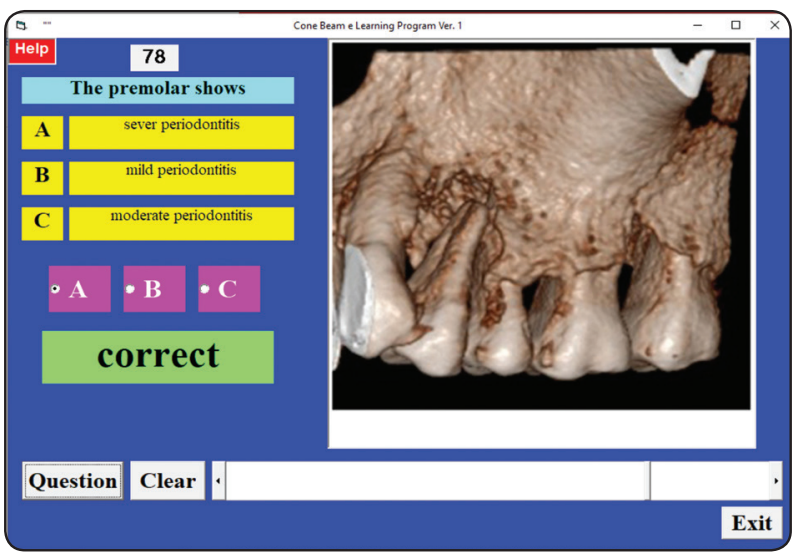

Fig. (6) Software layout displaying a MCQ about periodontitis on $\mathrm{CBCT}$ reformatted $3 \mathrm{D}$ view.

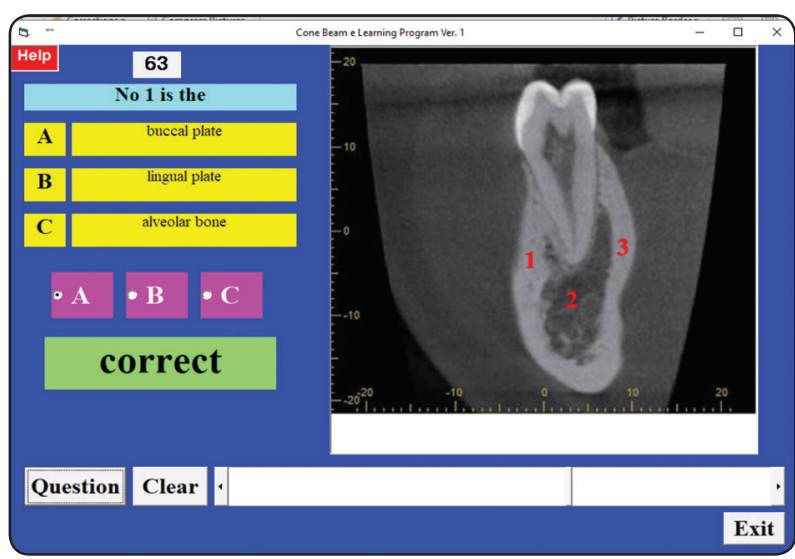

Fig. (3) Software layout displaying a MCQ about normal mandibular anatomical landmarks on CBCT image.

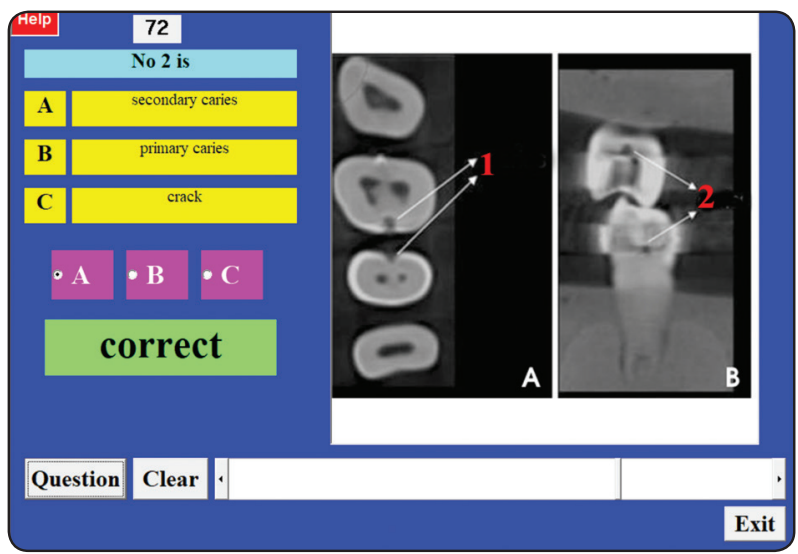

Fig. (5) Software layout displaying a MCQ about different types of carries on CBCT axial and coronal cuts.

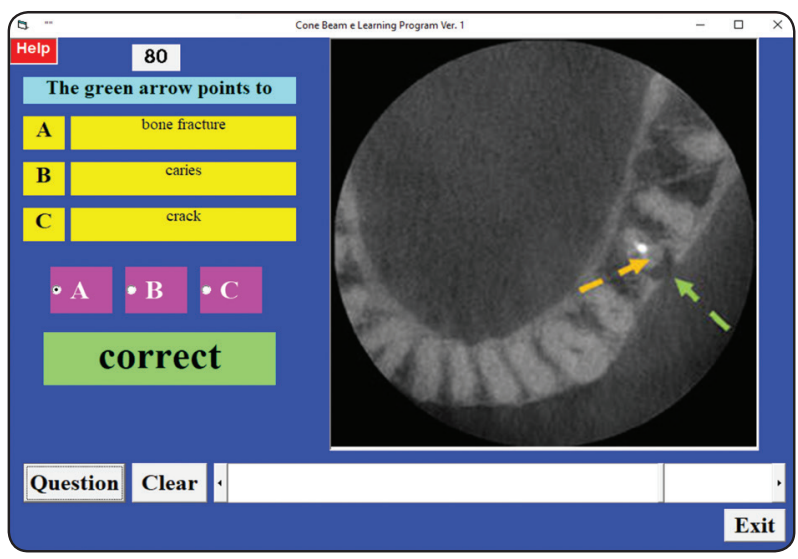

Fig. (7) Software layout displaying a MCQ about bone fracture on $\mathrm{CBCT}$ axial view. 


\section{RESULTS}

All of the 30 students had completed the study to the end and they were happy for participation. Results showed that the students had gained more degrees regarding the basic principles of $\mathrm{CT}$ and $\mathrm{CBCT}$, followed by the normal anatomical landmarks, followed by detection of caries and periapical lesions, followed by the detection of unfiled and extra root canals then lastly the cysts and tumors but cysts were more detected than tumors. Twenty marks were assigned for each category of the 5 divisions.

In group I results showed a mean score of $19.5 \pm 1.2$ for the basic principles of CT and CBCT compared to $16.1 \pm 2.3$ in group II with statistically significant differences at the $5 \%$ level of significance. Also the mean normal anatomical landmarks scores for group I was $18.7 \pm 1.7$ compared to $14.3 \pm 2.1$ in group II with statistically significant differences at the $5 \%$ level of significance. The mean scores for the detection of caries and periapical lesions were $16.5 \pm 1.5$ in group I compared to $13.7 \pm 2.6$ in group II with statistically significant differences at the $5 \%$ level of significance. However, the mean scores gained from the detection of unfiled and extra root canals were $15.6 \pm 1.3$ in group I compared to $12.9 \pm 1.9$ in group II with statistically significant differences at the $5 \%$ level of significance. Finally, the mean scores gained from the detection of cysts and tumors were $14.7 \pm 1.4$ in group I compared to
$11.8 \pm 1.6$ in group II with statistically significant differences at the $5 \%$ level of significance table 1 and graph1.

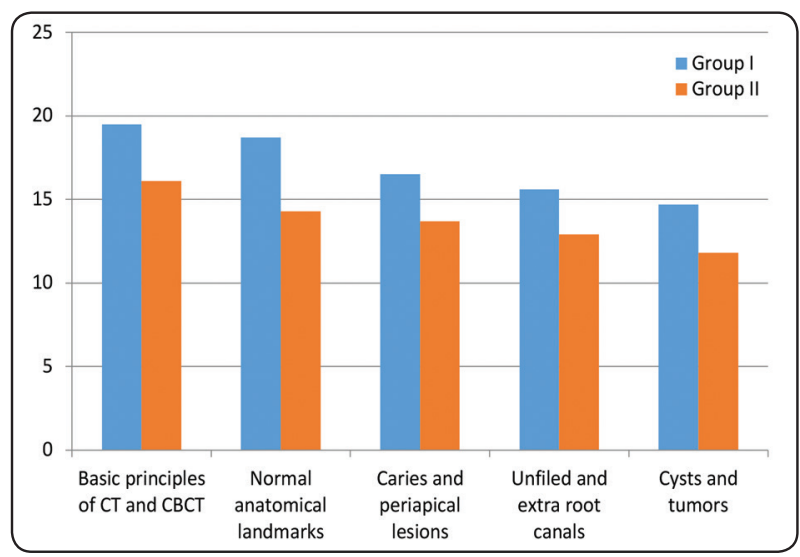

Graph (1) Shows the mean scores gained by the students in group I and group II.

\section{DISCUSSION}

The objectives of this study was to evaluate the validity of specially designed computer assisted learning (CAL) Visual Basic program containing images with multiple choice questions (MCQ) for learning the basics of CT and CBCT compared to lecture supplemented with PowerPoint presentation. Which has not applied before on CBCT in oral radiology courses.

As there were studies that evaluate e-learning in radiation physics, protection, or conventional radiographic technique, but they require varied

TABLE (1) Shows the mean scores gained by the students in group I and group II.

\begin{tabular}{|l|c|c|c|c|}
\hline \multicolumn{1}{|c|}{ Item } & Group I & Group II & t Value & P Value \\
\hline Basic principles of CT and CBCT & $19.5 \pm 1.2$ & $16.1 \pm 2.3$ & $5.07^{*}$ & 0.0001 \\
\hline Normal anatomical landmarks & $18.7 \pm 1.7$ & $14.3 \pm 2.1$ & $6.30^{*}$ & 0.0001 \\
\hline Caries and periapical lesions & $16.5 \pm 1.5$ & $13.7 \pm 2.6$ & $3.66^{*}$ & 0.0012 \\
\hline Unfiled and extra root canals & $15.6 \pm 1.3$ & $12.9 \pm 1.9$ & $4.54^{*}$ & 0.0001 \\
\hline Cysts and tumors & $14.7 \pm 1.4$ & $11.8 \pm 1.6$ & $5.28^{*}$ & 0.0001 \\
\hline
\end{tabular}

*= statistically significant differences at the 5\% level of significance. 
learning skills for achieving qualification and understanding, For the studies that include radiographic interpretation, the extent and topics were very different, ranging from normal basic anatomical landmark identification to pathological interpretation. ${ }^{[22]}$

The subject of the course designed in this study "CBCT" is considered one of the most challenging subjects in oral radiology as it becomes more incorporated into private practice as well as in clinical dental education. Adibi et al (2012) mentioned that it is important to dental school to add some fundamental CBCT education for both postdoctoral and predoctoral programs. Based on their survey, they believed that the principles of CBCT imaging, anatomical landmarks and radiological interpretation of diseases should be covered in predoctoral program and CBCT anatomy could be integrated into a first-year anatomical course or an introductory radiology course. ${ }^{[29]}$

The sample size in this study was 30 students divided into two groups, divided into two groups after attending a guiding lecture about the CBCT including the study images, group I were given the program $\mathrm{CD}$ while group II were allowed to review the lecture only, corresponding sample size was reported in other studies for evaluation of CD$\mathrm{ROM}$ or online learning content in the field of oral radiology. ${ }^{[30-33]}$

The CD was selected to contain the material of this study, due to its availability, low price, durability and easily use, in addition that the student can use them on any computer containing CD-ROM evenly at home. Moreover, the used Visual Basic program was simply to utilize, any student nowadays could handle its content without effort after reading the help, as he become familiar with the program.

The results of the current study reveals that the students had gained more degrees regarding the basic principles of $\mathrm{CT}$ and CBCT, the normal anatomical landmarks, detection of caries and periapical lesions, the detection of unfiled and extra root canals, respectively, then lastly the cysts and tumors but cysts were more detected than tumors. This variation in student scores with different topics may be attributed to the variation of difficulties among these topics specially the interpretation of cyst or tumors on a CBCT image. The results also showed statistically significant mean student's score in group I receiving the program CD containing the images with MCQ after lecture compared to the other group II. This results is beneficial in the field of diagnosis and it is in accordance with the prevalence of this lesion as Tavares et al (2017) ${ }^{[34]}$ were concluded that periapical granulomas were most frequently diagnosed from biopsies submitted by endodontist following apical surgery followed by radicular cyst, scars and other diagnoses.

The current study is in accordance with that of both Howerton et al (2002) ${ }^{[35]}$ and Deluiz et al (2005) $)^{[36]}$, who evaluate the development of multimedia CD-ROM having learning content about errors in exposing, processing and interpretation oral radiograph and they revealed that $\mathrm{CD}$ helped student visualize errors and the majority of student would use $\mathrm{CD}$ to study more topics in oral radiology.

Moreover, Such results agree with those of Nkenke (2012) $)^{[31]}$ who tried to send three multiple choice questions by email, to compare the technological- enhanced learning method with the traditional method, his learning content included radiation physics, x-ray production, interaction, radiation dose, equipment protection and normal radiological landmarks. They found that the group received that didatic course significantly better than the traditional.

Furthermore, the results agree with Silveira $(\mathbf{2 0 0 8})^{[33]}$ who evaluate the graphic application developed with power point in teaching bisecting angle technique, their results showed that the students who used the application accepted it well and their number of correct answers was significantly higher 
than that of the control group. Also silveira (2009) [32] concluded that CAL was found to be useful for learning cephalometry than conventional education.

The results of current study disagree with Howrton et al (2004) ${ }^{[10]}$ who tried to determine if the student performance varied when utilizing CAL activity using software or a lecture supplemented with power point. They concluded that no difference in student learning outcomes between lecture and CAL. However, their results indicate that student preferred the interactive instructional program and they mentioned that their CAL content did not include student testing, they attributed that to the needed software skills that dental educators may not have acquired as server input language.

Karemore et al (2016) ${ }^{[2]}$ evaluate specially designed CAL program containing cases of white keratotic lesions followed by MCQ for each case and they found significant improvement in student knowledge after using the program, mentioning that their program can be used as an adjunct to conventional teaching, which is the idea supported in the current study.

Although the use of multimedia approach in teaching and learning is called edutainment" or education and entertainment, it couldn't replace the traditional teaching methods including the face to face reaction ${ }^{[30]}$, This opinion is supported by Vuchkova et al (2012) ${ }^{[8]}$ who constructed digital interactive learning tools as on line resource and the results obtained from their study suggest that the majority of student felt that both the visual presentation of the digital tool and the conventional textual format were needed for learning radiographic anatomy.

Eventually, our study results is agreed with reviews introduced by both Zafar et al (2014) ${ }^{[37]}$ and Monier et al (2018) ${ }^{[9]}$ about evaluation of the effectiveness of digital educational resources in oral radiology education, they concluded that there were student positive attitudes, moreover a significant knowledge gain in most of the studies.
In the current study, students had good to very good skills in using CAL program, most of them found it interesting, had fun and happy being thought with the program. Beyond increasing student's motivation using CAL is seen as a possibility to increase the attractiveness of the university.

Using CAL program systems require new kinds of professional development, shifts in both curriculum and instructional goals.

\section{CONCLUSION}

- The use of CAL Visual Basic program provides enhancement, innovation and interactive way of learning of the basics of CBCT and allows opportunity to support the traditional methods of learning.

- Advanced software program containing questions with image should be used as an adjunct to conventional teaching as lectures for more balanced way of education.

\section{REFERENCES}

1. schittek m., M.N., Lyon HC. and Attstrom R., Computer assisted learning. A Review. Eur J Dent Educ, 2001. 5: p. 93-100.

2. Karemore TV., U.R.U., Motwani M., Karemore V. Introducing CALP (Computer assisted learning program) in Oral Medicine. MedEdPublish 2016.

3. Greenhalgh T, Computer assisted learning in undergraduate medical education. BMJ 2001. 322(7277): p. 40-4.

4. Plasschaert AJ, C.J., Verdonschot EH., The effect of a multimedia interactive tutorial on learning endodontic problem-solving. Eur J Dent Educ, 1997. 1(2): p. 66-9

5. Fall L, B.N., Smith S, et al, Multi-institutional development and utilization of a computer-assisted learning program for the pediatric clerkship. Acad Med, 2005. 80(9): p. 847-55.

6. Sandahl SS, Collaborative testing as a learning strategy in nursing education. Nurs Educ Perspect, 2010. 31: p. 142147.

7. Meckfessel S, S.C., Bormann KH, Kupka T, Behrends M, Matthies $\mathrm{H}$, et al., Introduction of e-learning in den- 
tal radiology reveals significantly improved results in final examination. J Cranio-Maxillofacial Surg, 2011. 39: p. $40-8$.

8. Vuchkova J, M.T., Farah CS. , Digital interactive learning of oral radiographic anatomy. Eur J Dent Educ., 2012. 16: p. 79-87.

9. Monier EB, A.D., de Oliveira AF, Fernandes AU,; Luana Martins CantanhedeLM, Furtado MM., The use of digital resources in the teaching of Dental Radiology: an integrative literature review. Revista da ABENO, 2018. 18(3): p. $75-83$.

10. Howerton WB, P.R.E.P., Ludlow JB, and Tyndall DA., Interactive Computer-Assisted Instruction vs. Lecture Format in Dental Education. Journal of Dental Hygiene, 2004. 78(4).

11. Ramesh A, G.R., Interactive learning in oral and maxillofacial radiology. Imaging Sci Dent., 2016. 46: p. 211-6.

12. Pahinis K, S.C., Walsh TF, Tsitrou E, Cannavina G. , A blended learning course taught to different groups of learners in a dental school: follow-up evaluation. J Dent Educ, 2008. 72: p. 1048- 1057.

13. Pahinis K, S.C., Walsh TF, Cannavina G. , Evaluating a blended-learning course taught to different groups of learners in a dental school. J Dent Educ, 2007. 71: p. 269-278.

14. Shah R., C.S., Implementation of the virtual learning environment into a UK orthodontic training programme: the postgraduate and lecturer perspective. . Eur J Dent Educ, 2009. 13: p. 223-232.

15. Linjawi AL, H.A., Perryer DG, Walmsley AD, Hill KB., Students' attitudes towards an on-line orthodontic learning resource. . Eur J Dent Educ, 2009. 13: p. 87-92.

16. Durham JA., B.S., Summerside C., McHanwell S., Evaluation of a virtual anatomy course for clinical undergraduates. . Eur J Dent Educ, 2009. 13: p. 100-109.

17. Farah CS, M.T., Implementing digital technology to enhance student learning of pathology. Eur J Dent Educ, 2009. 13: p. 172-178.

18. McKerlie RA., C.A., Matthew R., Evaluation of computer-assisted learning courseware to reinforce the teaching of removable partial denture design theory. Practice and Evidence of Scholarship of Teaching and Learning in Higher Education, April 2006. 1(1): p. 22-36.

19. Deshpande S. and Chahande J., Impact of computer-based treatment planning software on clinical judgment of dental students for planning prosthodontic rehabilitation. Adv
Med Educ Pract., Aug 2014 21(5): p. 269-74.

20. Al-Jewair TS, Q.A., Malkhassian G, Dempster LJ. , A Systematic Review of Computer-Assisted Learning in Endodontics Education. Journal of dental education June 2010. 74(6): p. 601-11.

21. Vuchkova J, M.T., Farah CS,, Digital interacitive learning of oral radiographic anatomy. Eur J Dent Educ, 2012. 16: p. 79-87.

22. Santos GNM, L.A., Figueiredo PT de S, Pimentel NM, Flores-Mir C, de Melo NS, et al. , Effectiveness of e-learning in oral radiology education: a systematic review. J Dent Educ. , 2016. 80: p. 1126-39.

23. ensino, C.E.M.d., aprendizagem no diagnóstico radiográfico das anormalidades ósseas dos maxilares [tese] Florianópolis: Faculdade de Engenharia e Gestão do Conhecimento. Universidade Federal de Santa Catarina;, 2012.

24. Zain-Alabdeen EH. and El Khateeb SM., Comparison of knowledge and perspectives toward cone-beam computed tomography among dentists in three Middle East regions: A cross-sectional study. Saudi J Oral Sci, 2018. 5: p. 3-10.

25. Parashar V., W.E., Monsour P., Chaudhry J., Geist JR. , Cone beam computed tomography in dental education: A survey of US, UK, and Australian dental schools. J Dent Educ, 2012.76: p. 1443-7.

26. Ramakrishnan P, S.F., Subhash A, Kumara A, Chakkarayan J, Vengalath J, et al. , Asurvey on radiographic prescription practices in dental implant assessment among dentists in Kerala, India. . Oral Health Dent Manag 2014. 13: p. 826-30.

27. Shetty SR, C.R., Babu SG, Laxmana AR, Roopashri K., Knowledge and attitude of dentists towards cone beam computed tomography in Mangalore - A questionnaire survey. . Austin J Radiol, 2015. 2: p. 1016.

28. Shah PH., V.R., Dental students' knowledge and attitude towards cone-beam computed tomography: An Indian scenario. Indian J Dent Res, 2016. 27: p. 581-5.

29. Adibi S, Z.W., Servos T, O’Neill PN,, Cone beam computed tomography in dentistry: What dental educators and learners should know. J Dent Educ, 2012. 76(11).

30. Nkenke E, V.E., Bauersachs A, et al. ,Acceptance of technology-enhanced learning for a theoretical radiological science course: a randomized controlled trial. BMC Med Educ, 2012. 12: p. 18. 
31. Nkenke E, V.E., Bauersachs A, et al., Spaced education activates students in a theoretical radiological science course: a pilot study. BMC Med Educ 2012. 12: p. 32.

32. Silveira HL, G.M., Silveira HE, Dalla-Bona RR., Evaluation of the radiographic cephalometry learning process by a learning virtual object. Am J Orthod Dentofacial Orthop, 2009. 136(1): p. 134-8.

33. Silveira HLD, L.G., Dalla-Bona RR, Silveira HE., Development of a graphic application and evaluation of teaching and learning of the bisecting-angle technique for periapical radiographs. Educação Formação Tecnologias, 2008. 1(2): p. 59-65.

34. Tavares D, R.J., dos Santos T, Armada L, Pires F,, Clinical and radiological analysis of a series of periapical cysts and periapical granulomas diagnosed in a Brazilian population. J Clin Exp Dent., 2017. 9(1): p. 129-35.

35. Howerton WBJ, P.E., Ludlow J, Tyndall DA., The influence of computer-assisted instruction on acquiring early skills in intraoral radiography. J Dent Educ 2002. 66(10): p. 1154-8.

36. Deluiz LF, C.A., Almeida CAP,, Avaliação do método auto-instrutivo no ensino para identificação dos erros na confecção de radiografias odontológicas. Rev Bras Odontol 2005. 62: p. 64-7.

37. Zafar S, S.S., Aasma N, Zafar b Evaluation of use of eLearning in undergraduate radiology education: A review. European Journal of Radiology 2014. 83: p. 2277-2287. 